DOI: 10.12731/2658-6649-2020-12-3-70-79

УДК 616.314

\title{
АНАЛИЗ СОСТОЯНИЯ ЗУБНЫХ РЯДОВ ПО ИНДЕКСУ РАСПРОСТРАНЕННОСТИ КАРИОЗНОГО ПРОЦЕССА - КПУ (З) У ЖИТЕЛЕЙ ПСИХОНЕВРОЛОГИЧЕСКИХ ИНТЕРНАТОВ ЗАПАДНОЙ ЗОНЫ КРАСНОЯРСКОГО КРАЯ, СТРАДАЮЩИХ УМСТВЕННОЙ ОТСТАЛОСТЬЮ
}

\author{
Чижов Ю.В., Радкевич А.А., Митрофанов П.В., \\ Бриль Е.А., Довнар С.А., Денисенко В.И., Саргсян И.И.
}

Цель. Определение состояния зубных рядов у жителей психоневрологических интернатов западной зоны Красноярского края, страдающих умственной отсталостью, с помощью индекса распространенности кариозного прочесса - КПУ(з).

Материалы и методы. Обследовано состояние зубных рядов у 387 (307 мужчин и 80 женщин) жителей психоневрологических интернатов западной зоны Красноярского края, страдающих умственной отсталостью. Из 307 мужчин 205 были взрослого (26-44 года) возраста, 76 мужчин зрелого возраста (45-59 лет) и 26 мужчин пожилого возраста (60-75). Из 80 женщин 54 были взрослого возраста (26-44 года), 13 женщин зрелого возраста (45-54 года), 13 женщин пожилого возраста (55-75 лет). Состояние зубных рядов было оченено с помощью индекса распространенности кариозного процесса - КПУ(з), который показывает оиенку интенсивности кариеса зубов среди популяиии.

Результаты. Изучение индекса интенсивности кариеса зубов - КПУ(з) у лии данной категории позволило выявить большую нуждаемость в различных видах стоматологической помощи, особенно в ортопедической более $90 \%$ во всех обследуемых возрастных группах в не зависимости от пола и возраста.

Заключение. Обследование с применением данного индекса КПУ(з) позволяет выявить, спланировать, привести к системе ортопедические, хирургические и терапевтические мероприятия в популяции жителей психоневрологических интернатов, страдающих умственной отсталостью.

Ключевые слова: умственная отсталость; индекс распространенности кариозного процесса. 


\section{THE ANALYSIS OF THE CONDITION OF TOOTH} ALIGNMENTS BY THE INDEX OF PREVALENCE OF CARIOUS PROCESS - THE KPU (Z) AT INHABITANTS OF THE PSYCHONEUROLOGICAL BOARDING SCHOOLS OF THE WESTERN ZONE OF KRASNOYARSK KRAI SUFFERING FROM INTELLECTUAL BACKWARDNESS

Chizhov Yu.V., Radkevich A.A., Mitrofanov P.V., Bril'E.A., Dovnar S.A., Denisenko V.I., Sarksyan I.I.

Purpose. Definition of a condition of tooth alignments at inhabitants of the psychoneurological boarding schools of the western zone of Krasnoyarsk Krai suffering from intellectual backwardness by means of the index of prevalence of carious process - KPU(z).

Materials and methods. The condition of tooth alignments at 387 (307 men and 80 women) inhabitants of the psychoneurological boarding schools of the western zone of Krasnoyarsk Krai suffering from intellectual backwardness is surveyed. From 307 men 205 were the adult (26-44 years) of age, 76 men of mature age (45-59 years) and 26 men of advanced age (60-75). From 80 women 54 were adult age (26-44 years), 13 women of mature age (45-54 years), 13 women of advanced age (55-75 years). The condition of tooth alignments was estimated by means of the index of prevalence of carious process - the KPU(z) which shows assessment of intensity of caries of teeth among population.

Results. Application of the modern index of intensity of caries of teeth-Kpu(z) allowed to reveal big needs in different types of the dental help, especially in orthopedic-90\% and more in all examined age groups are not dependent on gender and age.

Conclusion. Inspection with application of this index of the $K P U(z)$ allows to reveal, plan, lead to a system orthopedic, surgical and therapeutic actions in such not simple population as inhabitants of the psychoneurological boarding schools suffering from intellectual backwardness.

Keywords: mental retardation; index of prevalence of carious process.

\section{Введение}

Индекс КПУ является информативным показателем стоматологического здоровья населения как в целом, так и по отдельным составляющим данной специальности. Среднее количество кариозных зубов, выявленных при 
определении индекса, позволяет планировать объем лечебной работы, число пломбированных зубов - оценить качество стоматологической санации, а количество удаленных - необходимый объем ортопедической помощи [1-10].

\section{Цель исследования}

Определение состояния зубных рядов у жителей психоневрологических интернатов западной зоны Красноярского края, страдающих умственной отсталостью, с помощью индекса распространенности кариозного процесса - КПУ(3).

\section{Материалы и методы исследования}

Методом типологической выборки на территории Красноярского края (западная зона) был осуществлен выбор типичных психоневрологических интернатов, где проведено стоматологическое обследование 307 мужчин и 80 женщин, страдающих умственной отсталостью. Обследованные лица были распределены на 3 возрастные категории: 1. Взрослый возраст - 205 мужчин (26-44 года); 54 женщины (26-44 года); 2. Зрелый возраст - 76 мужчин (45-59 лет); 13 женщин (45-54 года); 3. Пожилой возраст - 26 мужчин (60-75 лет); 13 женщин (55-75 лет).

У всех обследованных определяли состояние твердых тканей зубов по индексу распространенности кариозного процесса - КПУ(з).

КПУ(з) - это сумма кариозных, пломбированных (пломба, ортопедические конструкции: вкладки, коронки) и удаленных зубов одного индивидуума.

ВО3 различает 5 уровней интенсивности кариеса зубов и предлагает следующие оценочные критерии по индексу КПУ для 2 ключевых групп: 12 лет и 35-44 лет (табл. 1) [1]. Для сравнения использовали средние значения индекса КПУ.

Таблица 1.

Характеристика и показатели интенсивности кариеса зубов по ВОЗ в зависимости от возраста

\begin{tabular}{|l|c|c|}
\hline $\begin{array}{c}\text { Уровень интенсив- } \\
\text { ности кариеса }\end{array}$ & $\begin{array}{c}\text { Показатель интенсивности } \\
\text { кариеса (КПУ)-12 лет }\end{array}$ & $\begin{array}{c}\text { Показатель интенсивности } \\
\text { кариеса (КПУ) - 35-44 года }\end{array}$ \\
\hline Очень низкий & $0,0-1,1$ & $0,2-1,5$ \\
\hline Низкий & $1,2-2,6$ & $1,6-6,2$ \\
\hline Средний & $2,7-4,4$ & $6,3-12,7$ \\
\hline Высокий & $4,5-6,5$ & $12,8-16,2$ \\
\hline Очень высокий & 6,6 и выше & 16,3 и выше \\
\hline
\end{tabular}




\section{Результаты исследования}

Анализ компонентов индекса КПУ у лиц взрослого возраста (26-44 года) с умственной отсталостью показал, что среднее число удаленных зубов на одного человека как у мужчин $(19,92)$ так и у женщин $(20,07)$, как минимум в 10 раз превышает число кариозных $(1,61$ и 1,84) и число запломбированных зубов $(0,36$ и 0,46$)$ соответственно. У мужчин среднее число кариозных зубов $(1,61)$ в 4,4 раза превышает аналогичный показатель пломбированных зубов $(0,36)$. У женщин результат аналогичен: среднее число кариозных зубов $(1,84)$ в 4 раза выше числа пломбированных зубов $(0,46)$ (табл. 2). Индекс КПУ у мужчин и женщин взрослого возраста значительно выше самого наихудшего нормативного показателя для данной возрастной группы, т.е - 16,3 [1].

Компоненты индекса КПУ у мужчин и женщин зрелого возраста, страдающих умственной отсталостью, как и у лиц предыдущей группы, преобладали средние значения удаленных зубов (20,57 у мужчин и 20,07 у женщин) над кариозными $(1,93$ и 1,84$)$ и пломбированными зубами $(0,44$ и 0,46$)$ соответственно. Индекс КПУ у мужчин - 22,94, у женщин - 22,37 оставался в тех же высоких значениях, что и у лиц взрослого возраста (табл. 3) и также значительно превышал предельный стандартный уровень для данного возраста.

Таблициа 2.

\section{Показатели индекса КПУ и его компонентов}

у лиц взрослого (26-44 года), страдающих умственной отсталостью

\begin{tabular}{|c|c|c|c|c|c|}
\hline \multirow{2}{*}{\multicolumn{2}{|c|}{$\begin{array}{c}\text { Индексы КПУ } \\
\text { и его компоненты }\end{array}$}} & \multicolumn{2}{|r|}{$\begin{array}{c}\text { Мужчины } \\
(\mathrm{n}=205)\end{array}$} & \multicolumn{2}{|r|}{$\begin{array}{l}\text { Женщины } \\
\text { (n=54) }\end{array}$} \\
\hline & & число & & & \\
\hline \multirow{3}{*}{$\begin{array}{c}\text { Кариозные } \\
\text { зубы }\end{array}$} & коронки & 226 & 1,10 & 18 & 1,38 \\
\hline & корни & 104 & 0,50 & 6 & 0,46 \\
\hline & всего & 330 & 1,61 & 24 & 1,84 \\
\hline \multicolumn{2}{|c|}{$\begin{array}{l}\text { Пломбированные } \\
\text { зубы }\end{array}$} & 74 & 0,36 & 6 & 04,46 \\
\hline \multicolumn{2}{|c|}{ Удаленные зубы } & 4085 & 19,92 & 261 & 20,07 \\
\hline \multicolumn{2}{|l|}{ Всего зубов } & \multicolumn{2}{|r|}{4484} & \multicolumn{2}{|r|}{291} \\
\hline \multicolumn{2}{|c|}{ Индекс КПУ } & \multicolumn{2}{|r|}{23,46} & \multicolumn{2}{|r|}{22,37} \\
\hline
\end{tabular}


Siberian Journal of Life Sciences and Agriculture, Vol. 12, №3, 2020

Таблицуа 3.

Показатели индекса КПУ и его компонентов у лиц зрелого возраста мужчин (45-59 лет), женщин (45-54 года), страдающих умственной отсталостью

\begin{tabular}{|c|c|c|c|c|c|}
\hline \multirow{2}{*}{\multicolumn{2}{|c|}{$\begin{array}{c}\text { Индексы КПУ } \\
\text { и его компоненты }\end{array}$}} & \multicolumn{2}{|c|}{$\begin{array}{c}\text { Мужчины } \\
(\mathrm{n}=76)\end{array}$} & \multicolumn{2}{|c|}{$\begin{array}{c}\text { Женщины } \\
(n=13)\end{array}$} \\
\hline & & число & среднее & число & среднее \\
\hline \multirow{3}{*}{$\begin{array}{c}\text { Кариозные } \\
\text { зубы }\end{array}$} & коронки & 107 & 1,40 & 18 & 1,38 \\
\hline & корни & 40 & 0,53 & 6 & 0,46 \\
\hline & всего & 147 & 1,93 & 24 & 1,84 \\
\hline \multicolumn{2}{|c|}{ Пломбированные зубы } & 34 & 0,44 & 6 & 0,46 \\
\hline \multicolumn{2}{|c|}{ Удаленные зубы } & 1564 & 20,57 & 261 & 20,07 \\
\hline \multicolumn{2}{|l|}{ Всего зубов } & \multicolumn{2}{|r|}{1745} & \multicolumn{2}{|r|}{291} \\
\hline \multicolumn{2}{|l|}{ Индекс КПУ } & \multicolumn{2}{|r|}{22,94} & \multicolumn{2}{|r|}{22,37} \\
\hline
\end{tabular}

При анализе компонентов индекса КПУ у лиц пожилого возраста, страдающих умственной отсталостью, установлено, что соотношение удаленных зубов к кариозным и пломбированным и кариозных зубов к пломбированным возрастало. Так, среднее число удаленных зубов на одного человека у мужчин $(20,30)$ по отношению к среднему числу кариозных $(1,84)$ в 11 раз выше, а у женщин данное соотношение выше в 13,4 раза $(24,6$ против 1,84$)$ соответственно. У мужчин среднее число кариозных зубов $(1,38)$ лишь в 2 раза превышало среднее число пломбированных $(0,61)$, у женщин оно было еще меньше - в 1,3 раза $(1,84$ к 1,38$)$ соответственно. Индекс КПУ у мужчин пожилого возраста составил 22,75, у женщин 26,8, что выше среднего уровня КПУ по России для лиц старше 65 лет - 21,79 (табл. 4).

Сравнивая основной количественный компонент индекса КПУ (удаленные зубы) трех возрастных групп, можно выявить следующее процентное соотношение по группам. Мужчины: взрослый возраст - 91,1\%; зрелый возраст - 89,6\%; пожилой возраст - 89,0\%. Женщины: взрослый возраст - 89,6\%; зрелый возраст - 89,6\%; пожилой возраст - 91,4\%.

Показатели среднего числа кариозных зубов чрезвычайно малы и не имели тенденции к изменению с возрастом. Мужчины: взрослый возраст 1,61 ; зрелый возраст - 1,93; пожилой возраст - 1,84. Женщины: взрослый возраст - 1,84; зрелый возраст - 1,84; пожилой возраст - 1,84. 
Таблица 4.

Показатель индекса КПУ и его компонентов у лиц пожилого возраста: мужчин (60-74 года); женщин (55-74 года); страдающих умственной отсталостью

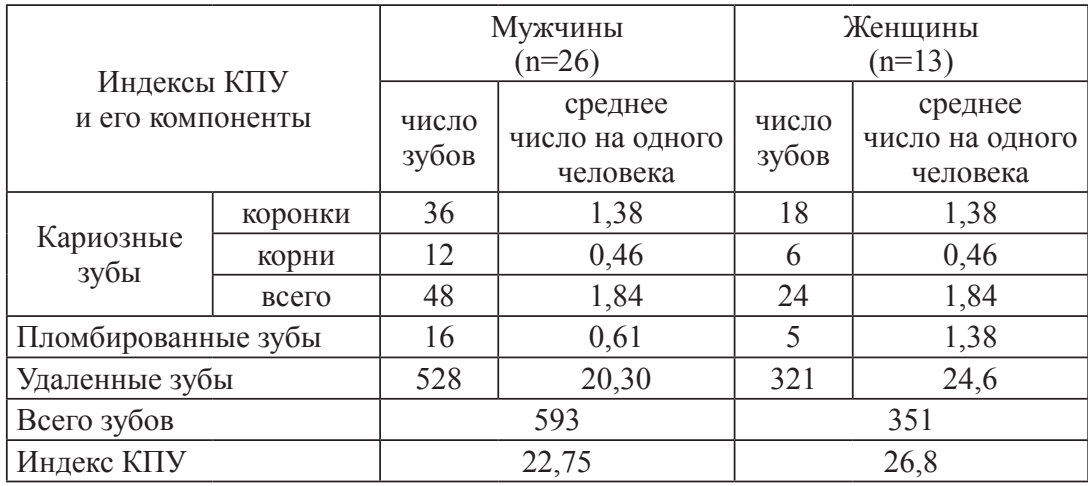

Показатели среднего числа пломбированных зубов имели малые величины, и, также, как и показатели кариозных зубов не имели тенденции к существенным изменениям с возрастом. Мужчины: взрослый возраст 0,36; зрелый возраст - 0,44; пожилой возраст - 0,61. Женщины: взрослый возраст $-0,46$; зрелый возраст - 0,46; пожилой возраст - 1,38.

Индекс КПУ во всех возрастных группах был очень высок. Мужчины: взрослый возраст - 23,46; зрелый возраст - 22,94; пожилой возраст $-22,75$. Женщины: взрослый возраст - 22,37; зрелый возраст - 22,37; пожилой возраст $-26,8$.

\section{Заключение}

При анализе структуры КПУ лиц с умственной отсталостью взрослого, зрелого и пожилого возраста выявлено подавляющее преимущество доли среднего числа удаленных зубов во всех группах. Доля среднего числа кариозных зубов в каждой возрастной группе в 2 раза больше доли пломбированных как у мужчин, так и у женщин. Индекс КПУ в обследуемых группах у мужчин с возрастом стабилен, но очень высок, у женщин имел тенденцию к увеличению.

Величина индекса КПУ во всех группах лиц данной категории, проживающих в психоневрологических интернатах западной зоны Красноярского края превышало средние значения по России. В структуре индекса удаленные зубы значительно преобладали над кариозными и пломбированными. По данным индекса КПУ(з) и его компонентов наибольшая ну- 
ждаемость выявлена в ортопедической стоматологической помощи $-90 \%$ и более во всех возрастных группах вне зависимости от пола и возраста.

\section{Список литературы}

1. Бабина К.С. Сравнительный анализ индексов гигиены полости рта // Modern problems and ways of their Solution in science, transport, production and education. 2012. https://www.sworld.com.ua/konfer 29/753.pdf

2. Кузьмина Э.М. Профилактика стоматологических заболеваний: учебное пособие. М.: Тонга-Принт, 2001. 216 с.

3. Максимовский Ю.М. Терапевтическая стоматология / Ю.М. Максимовский, А.В. Митронин. М.: Гэотар-Медиа, 2012. 322 с.

4. Пародонтология / Г.Ф. Вольф, Э.М. Ратейцхак; Пер.с нем.; Под ред. Г.М. Барера. М.: МЕДпресс-информ, 2008. 548 с.

5. Терапевтическая стоматология : учебник : в 3 ч. / Под ред. Г.М. Барера. М.: ГЭОТАР-Медиа, 2005. Ч. 3. 288 с.

6. Фарниева О.А. Распространенность и интенсивность кариеса в различных экологических эонах РСО - Алания / О.А. Форниева, 3.Р. Аликова // Владикавказский медико-биологический вестник. 2010. Т.11, №18. С. 119-126.

7. Чижов Ю.В. Характеристика состояния зубных рядов по индексу КПУ у лиц пожилого и старческого возраста, проживающих в домах-интернатах Восточной Сибири / Ю.В. Чижов, С.Ю. Чаптыков, О.М. Новиков // Dental forum. 2011, №2[38]. С. 41-43.

8. Чижов Ю.В. Методика комплексной оценки состояния стоматологического здоровья людей пожилого и старческого возраста / Ю.В. Чижов, А.В. Цимбалистов, О.М. Новиков: Методическое пособие. Красноярск, 2005. 53 с.

9. Цимбалистов А.В. Особенности стоматологического и соматического статуса пациентов пожилого и старческого возраста / А.В. Цимбалистов, Е.С. Михайлова, О.Л. Пикур и др. // Вестн. Санкт-Петербургского университета. 2006, Сер.11 (вып.4). С. 1-9.

10. Яковлева В.И. Диагностика, лечение и профилактика стоматологических заболеваний / В.И. Яковлева, Е.К. Трофимова, Т.П. Давидович. - Минск: «Высшая школа», 1995. 493 с.

\section{References}

1. Babina K.S. Sravnitel'nyj Analiz indeksov gigieny polosti rta [Comparative analysis of oral hygiene indices]. Modern problems and ways of their Solution in science, transport, production and education. 2012. https://www.sworld.com. ua/konfer29/753.pdf 
2. Kuz'mina EH.M. Profilaktika stomatologicheskih zabolevanij [Prevention of dental diseases: studies. manual]. M., 1997. 136 p.

3. Maksimovskiy Y.M., Mitronin A.V. Terapevticheskaja stomatologija [Therapeutic dentistry]. Moscow: GEOTAR-Media, 2012. 322 p.

4. Vol'f G.F., Ratejckhak Eh.M. Parodontologiya [Periodontics]. / ed. G.M. Barera. M.: MEDpress-inform. 2008. 548 p.

5. Terapevticheskaja stomatologija: uchebnik [Therapeutic dentistry: textbook]: in 3 hours / edited by G.M. Barer. Moscow: GEOTAR-Media, 2005. Part 3. 288 p.

6. Farnieva O.A., Alikova Z.R. Vladikavkazskiy mediko-biologicheskiy vestnik. 2010. V.11, №18, pp. 119-126.

7. Chizhov Yu.V, Chaptykov S.Yu., Novikov O.M. Characteristics of the state of dental rows according to the CPI index in elderly and senile people living in boarding houses in Eastern Siberia [Harakteristika sostojanija zubnyh rjadov po indeksu KPU u lits pozhilogo i starcheskogo vozrasta, prozhivajuschih v domah-internatah Vostochnoj Sibiri]. Dental forum. 2011, № 2[38], pp. 41-43.

8. Chizhov Yu.V., Cimbalistov A.V., Novikov O.M. Metodika kompleksnoj ocenki sostoyaniya stomatologicheskogo zdorov'ya lyudej pozhilogo i starcheskogo vozrasta [Methods of comprehensive assessment of the dental health of people in the elderly and senile age: method. allowance]. Krasnoyarsk. 2005. 53 p.

9. Cimbalistov A.V., Mihajlova E.S., Pikur O.L. i dr. Osobennosti stomatologicheskogoi somaticheskogo statusa pacientov pozhilogo i starcheskogo vozrasta [Features of the dental and somatic status of patients of elderly and senile age]. Vestn. SPb un-ta [Bulletin of St. Petersburg University]. Ser.11. 2006. № 4, pp. 1-9.

10. Yakovleva V.I., Trofimova E.K., Davidovich T.P. Diagnostika, lechenie i profilaktika stomatologicheskih zabolevanij [Diagnosis, treatment and prevention of dental diseases]. Minsk: Vyssh. shk. 493 p.

\section{ДАННЫЕ ОБ АВТОРАХ}

Чижов Юрий Васильевич, Д.м.Н., профессор ФГБОУ ВО КрасГМУ им. проф. В.Ф. Войно-Ясенецякого Минздрава России

ул. Партизана Железняка, 1, г. Красноярск, 660022, Российская Федерачия gullever@list.ru

Радкевич Андрей Анатольевич, д.м.н., профессор кафедры-клиники хирургической стоматологии КрасГМУ 
ФГБОУ ВО КрасГМУ им. проф. В.Ф. Войно-Ясенецкого Минздрава России

ул. Партизана Железняка, 1, г. Красноярск, 660022, Российская Федерачия

radkevich.fndrey@yandex.ru

Митрофанов Павел Викторович, врач-ортопед-стоматолог

КГБУЗ КГСП № 7 г.Красноярска

ул. Парашютная, 82, г. Красноярск, 660121, Российская Федераџия pavel.mitrofanov.71@mail.ru

Бриль Елена Александровна, д.м.н., доцент кафедры-клиники стоматологии детского возраста и ортодонтии ФГБОУ ВО КрасГМУ им. проф. В.Ф. Войно-Ясенеичкого Минздрава России

ул. Партизана Железняка, 1, г. Красноярск, 660022, Российская Федерачия

e.a.b.27@mail.ru

Довнар Светлана Антоновна, врач-стоматолог

КГБУЗ Красноярский межрайонный родильный дом 4 ул. Коломенская, 26, г. Красноярск, Российская Федераџия gullever@list.ru

Денисенко Владимир Иванович, врач ортопед-стоматолог

КГБУЗ Сосновоборская городская больнииа, стоматологическое отделение

ул. Солнечная, 8, г. Сосновоборск, Красноярский край, Российская Федераиия

gullever@list.ru

Саргсян Ирина Ивановна, главный врач

ООО «Стоматология для Вас»

ул. Тельмана, 32a, г. Красноярск, 660073, Российская Федераџия stomDV@mail.ru

DATA ABOUT THE AUTHORS

Chizhov Yurij Vasil'evich, MD, Professor 
Krasnoyarsk State Medical University named after Prof. V.F.Voino-Yasenetsky

1, Partizan Zheleznyak Str., Krasnoyarsk, 660022, Russian Federation gullever@list.ru

Radkevich Andrej Anatol'evich, MD, Professor of Department Clinic of Surgical Stomatology

Krasnoyarsk State Medical University named after Prof. V.F.Voino-Yasenetsky 1, Partizan Zheleznyak Str., Krasnoyarsk, 660022, Russian Federation radkevich.fndrey@yandex.ru

Mitrofanov Pavel Viktorovich, Orthopedic Dentist Krasnoyarsk state dental policlinics № 7 82, Parashutnaya Str., Krasnoyarsk, 660121, Russian Federation pavel.mitrofanov.71@mail.ru

Bril' Elena Aleksandrovna, MD, Associate Professor of Department Clinic of Stomatology of Children's Age and Orthodontics

Krasnoyarsk State Medical University named after Prof. V.F.Voino-Yasenetsky

1, Partizan Zheleznyak Str., Krasnoyarsk, 660022, Russian Federation e.a.b.27@mail.ru

Dovnar Svetlana Antonovna, Dentist

Krasnoyarsk Interdistrict Maternity Hospital 4

26, Kolomenskaya St., Krasnoyarsk, Russian Federation

gullever@list.ru

Denisenko Vladimir Ivanovich, Dentist Orthopedist

Sosnovoborsk City Hospital

8, Solnechnaya Str., Sosnovoborsk, Krasnoyarsk Region, Russian Federation

gullever@list.ru

Sargsyan Irina Ivanovna, Head Physician

Dentistry for you, $L L C$

32a, Telman Str., Krasnoyarsk, 660073, Russian Federation stomDV@mail.ru 